\title{
SPIONs' Enhancer Effect on Cell Transfection: An Unexpected Advantage for an Improved Gene Delivery System
}

Laura Balcells, ${ }^{\dagger}$ Cristina Fornaguera, ${ }^{\dagger}$ Pau Brugada-Vilà, ${ }^{\dagger}$ Marta Guerra-Rebollo,,$\|, \perp$

Óscar Meca-Cortés, ${ }^{\|, \perp}$ Gema Martínez, ${ }^{\S}$ Núria Rubio, ${ }^{\|, \perp}$ Jerónimo Blanco, ${ }^{\|, \perp}$ Jesús Santamaría, ${ }^{\S, \| \oplus ~}$

Anna Cascante, ${ }^{\ddagger}$ and Salvador Borrós*, $*, \neq, \|_{\odot}$

${ }^{\dagger}$ Grup d’Enginyeria de Materials (GEMAT) - Institut Químic de Sarrià (IQS), Universitat Ramon Llull (URL), Via Augusta 390, 08017 Barcelona, Spain

${ }^{\ddagger}$ Sagetis Biotech SL, Via Augusta 394, 08017 Barcelona, Spain

${ }^{\S}$ Grupo de Superfícies y Partículas Nanoestructuradas, Instituto de Nanociencia de Aragón (INA), Campus Río Ebro, Edif. I+D, C/ Mariano Esquillor Gómez, S/N, 50018 Zaragoza, Spain

"CIBER of Biomaterials, Bioengineering and Nanomedicine (CIBER-BBN), Av. Monforte de Lemos, 3-5, Pabellón 11, Planta 0, 28029 Madrid, Spain

${ }^{\perp}$ Institute of Advanced Chemistry of Catalonia (IQAC-CSIC), C7 Jordi Girona Salgado, 18-24, 08034 Barcelona, Spain

\section{Supporting Information}

ABSTRACT: The clinical implantation of gene therapy is hindered by the limitations of current gene delivery vectors, namely, safety issues regarding viral vectors and low transfection efficacy regarding nonviral vectors. Thus, the design of safe and efficient gene carriers is a key point for the success of such therapies. In addition, when employing genetically modified cells for further applications, the selection of successfully modified cells becomes crucial. To address these issues, we have developed multicomponent nanoparticles composed of poly(B-amino ester) (pBAE) polymers, plasmid DNA, and superparamagnetic iron oxide nanoparticles (SPIONs). Whereas pBAEs were initially employed

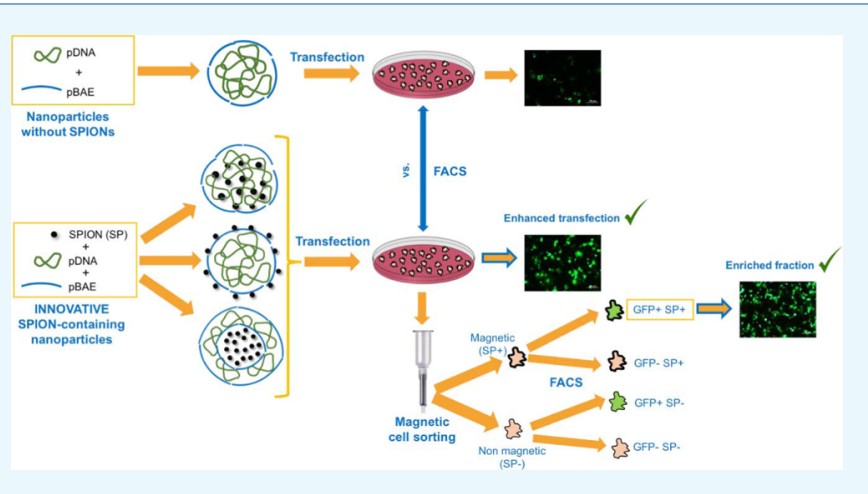
as safe and biocompatible carriers with improved transfection efficiency, as compared to commercial vectors, SPIONs were used because of their magnetic character that enables cell selection. Surprisingly, the results presented here revealed an unexpected enhancer effect of SPIONs on the transfection efficiency of $\mathrm{pBAE} / \mathrm{pDNA}$ polyplexes in both permissive and reluctant to transfection cell lines. This unanticipated outcome, together with the allowance to perform a selective magnetic sorting of genetically modified cells without interfering in cell transfection, opens the door to SPION-containing nanoparticles as promising tools for cell therapy approaches.

\section{INTRODUCTION}

Gene therapy emerged as a pioneering technique to treat or improve the health condition of patients by modifying their cells genetically. Although it aroused huge expectations, the number of gene therapeutic products in the market is limited and does not correlate with numerous lab-scale research studies. The major historical problem is the development of efficient and safe systems for the delivery of therapeutic genes into the target cells. Depending on their origin, gene delivery vectors can be divided into two types: viral and nonviral. Viral vectors have naturally evolved to infect cells with high efficiency. However, they imply some important drawbacks, safety concerns being the main issue to circumvent. In addition, they have limited packaging capacity and have an expensive large-scale production. ${ }^{1-3}$ Furthermore, viral vectors often show poor tissue and organ target-specificity and are susceptible to neutralization by serum antibodies and the complement system. ${ }^{4-6}$ On the contrary, nonviral gene carriers, although showing lower transfection efficiency when compared to viruses, have become an alternative of great interest in the last few decades as they offer many relevant advantages. These systems not only overcome major viral delivery toxicity problems but also have other worthwhile properties including in vivo stability, low-cost production, facility to scale up their production, and the ease of synthesis and modification. ${ }^{7-10}$ The most widely used nonviral systems are complexes formed by the electrostatic interaction of nucleic acids with cationic lipids (lipoplexes) and/or cationic polymers (polyplexes). The latter are advantageous in terms of versatility in their design, large DNA cargo capacity, the possibility of being rationally synthesized incorporating functional groups with relative ease

Received: October 22, 2018

Accepted: January 3, 2019

Published: February 6, 2019 
and flexibility, and the ability to more efficiently condense DNA than lipoplexes. ${ }^{11}$ In the last few years, polyplexes encapsulating DNA or RNA have gained importance in this field due to their lower liver accumulation rates when used for in vivo applications. $^{12,13}$ However, their fairly low transfection efficiency remained a major drawback. ${ }^{14}$ For this reason, in the last few years, researchers devoted many efforts to improve their transfection efficiency employing different strategies. ${ }^{15,16}$

Recently, a class of cationic, biodegradable polymers known as poly $(\beta$-amino ester)s (pBAEs) has been developed as promising nucleic acid delivery systems. ${ }^{17,18}$ These polymers possess a high transfection efficacy in vitro and in vivo, together with low toxicity and the ability for ligand-specific uptake. Their capacity to efficiently complex nucleic acids into discrete nanoparticles and transfer genetic material to target cells makes them suitable as gene delivery vectors for cell therapy applications. ${ }^{19}$ Furthermore, our group has developed a family of poly $(B-$ amino ester) polymers with oligopeptide-modified termini (OM-pBAEs) that proved increased transfection efficiency in cell-type-specific manner and excellent biocompatibility. These previous results have demonstrated that tailored formulations of different cationic OM-pBAE polymers are capable of rendering nanoparticles with specific features, such as cell specificity or intracellular localization. ${ }^{20}$ More recently, our group has expanded the use of this oligopeptide end-modification through the use of mixtures of both cationic and anionic OM-pBAE polymers as delivery systems for siRNA, leading to a simple method to tailor the surface charge of the resulting nanoparticles, while maintaining their ability to mediate efficient gene silencing. ${ }^{21}$ Finally, it has been reported the possibility of tuning the hydrophilicity-hydrophobicity ratio of pBAE formulations to obtain particles with higher siRNA packaging capacity and increased stability. ${ }^{22}$ All these advantageous characteristics, especially their high transfection efficiency and their safety profile, confer OM-pBAEs a high suitability as gene delivery vectors.

Genetically modified cells can next be employed for several further purposes including immunotherapy, stable transgene expression in eukaryotic cells, theranostics, ex vivo models for clinical applications, and cell therapy strategies. ${ }^{23-30}$ Most of these applications, specially the ones related to cell therapy, require a selection of successfully modified cells to increase the probabilities of achieving a final beneficial effect, and, therefore, the enrichment and selection of genetically modified cells become a key matter. ${ }^{31}$ At this point, and given the current growing interest in the combination of both gene and cell therapy strategies, a system allowing simultaneously the genetic modification of cells and their later selection for in vivo implantation would be of great interest.

Cell therapy is an emerging approach showing promising results in many fields such as bone marrow transplants, diabetes mellitus treatment, ${ }^{30}$ cardiovascular disease, ${ }^{32}$ bone engineering, $^{33}$ and the treatment of articular cartilage lesions (focal defects, osteoarthritis). ${ }^{34}$ This procedure relies on replacing damaged or dysfunctional cells or tissues with healthy, functioning ones. The cells used for cell therapy applications are usually stem cells obtained from the same patient (autologous) or from a compatible donor (allogeneic) to repair the damaged tissue. In addition, the possibility to genetically modify these therapeutic cells has opened a door toward the development of new therapies applied not only to tissue regeneration, but also to many genetic diseases, including blood cell diseases such as hemophilia and cancer. ${ }^{29}$ In these cases, genetically modified cells are often administered to patients with therapeutic purposes. These strategies imply as main hindrance the susceptibility of therapeutic (stem) cells to be used by the tumors to promote their own growth due to their capacity to differentiate into other cell types. ${ }^{35}$ Therefore, using them requires the selection of modified cells to ensure that only the therapeutic ones are delivered to patients, thus increasing the probabilities of the therapy to success and decreasing side effects.

The two most common ways to perform cell sorting are based either on fluorescence or on magnetism. Magnetic labeling is frequently easier, cheaper, and quicker than dying or modifying cells to express a fluorescent protein. ${ }^{36,37}$ Moreover, if polymers are fluorescently labeled (modified), they will differ from the original ones and consequently end in regulatory hurdles. Besides, for further clinical applications, which always imply scale-up processes, these advantages become even more relevant. For these reasons, in this work, a magnetic cell sorting was proposed, specifically, using superparamagnetic iron oxide nanoparticles (SPIONs), a type of magnetic nanoparticles (MNPs). They were selected because they have been used, to date, as (a) contrast agents for magnetic resonance imaging and magnetic-cell-labeled tracking in diagnostic applications ${ }^{38-40}$ and (b) for magnetofection, which is a transfection technique that uses magnetic fields to attract particles containing magnetic nanoparticles into cells. ${ }^{41-43}$ The strategy proposed here is the use of SPIONs to select the transfected cells taking advantage of their magnetic feature and with the ambition of achieving higher transfection efficiencies through magnetic cell sorting. The proof-of-concept detailed hereafter could be of great interest for further use in stem cells for cell therapy strategies.

We plan to overcome two of the main challenges previously described, namely, (1) obtain high levels of gene transfection in a safe manner and (2) separate the genetically modified cells from the ones that do not carry the therapeutic gene using a novel multicomponent nonviral gene delivery vector. The new SPION-containing nanoparticles will be characterized by different physicochemical techniques. The expression of the reporter gene green fluorescent protein (GFP) will be used to evaluate the transfection efficiency of these novel SPIONcontaining nanoparticles and to compare this parameter between the nanoparticles with and without SPIONs. These tests will be performed using different in vitro cell cultures, ranging from a permissive cell line to a highly difficult-totransfect one. Additionally, a sorter of transfected cells will be performed exploiting the magnetic feature of SPIONs to positively select and, therefore, enrich the fraction of transfected cells.

To sum up, the approach presented in this work is based on the combination of polyplexes, formed by plasmid DNA and OM-pBAEs, together with SPIONs. The specific structure and composition of the resulting nanoparticles will allow not only the separation of the genetic modified cells from the ones that do not contain the foreign DNA by applying an external magnetic field, but also an unexpected enhancement on cell transfection.

\section{RESULTS AND DISCUSSION}

Manufacturing of SPION-Containing Nanoparticles. In the present work, 2,3-dimercaptosuccinic acid (DMSA)-coated SPIONs $^{44,45}$ were employed. These SPIONs have been proven to have excellent properties in terms of efficiency and biocompatibility for application to target cancer cells such as MCF-7 breast cancer cells ${ }^{46}$ and have been already used for 
A

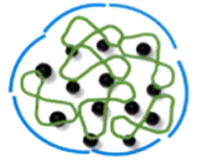

" $\mathrm{T}$ "

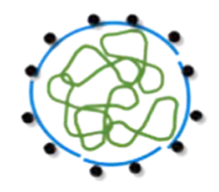

"S"

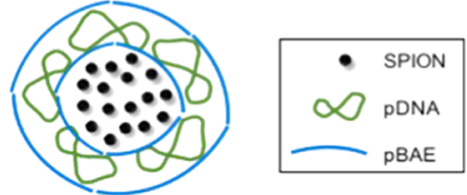

"M"

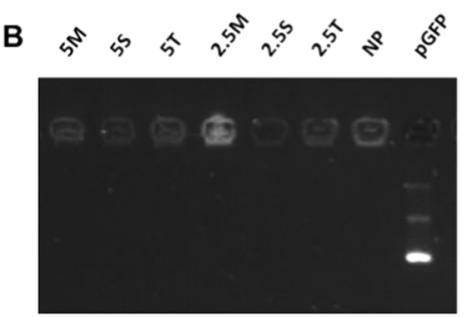

C

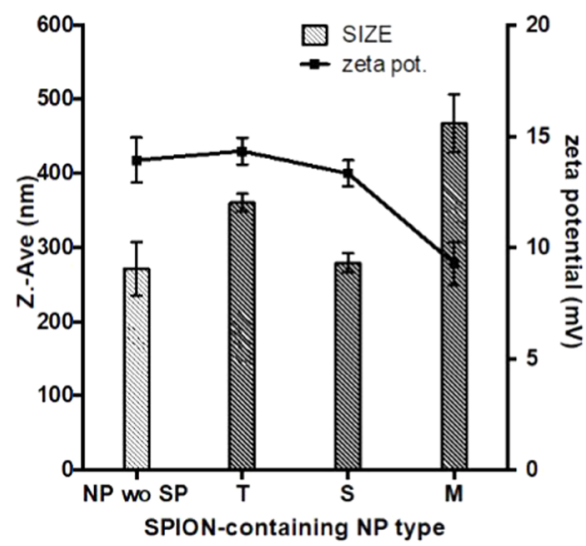

D

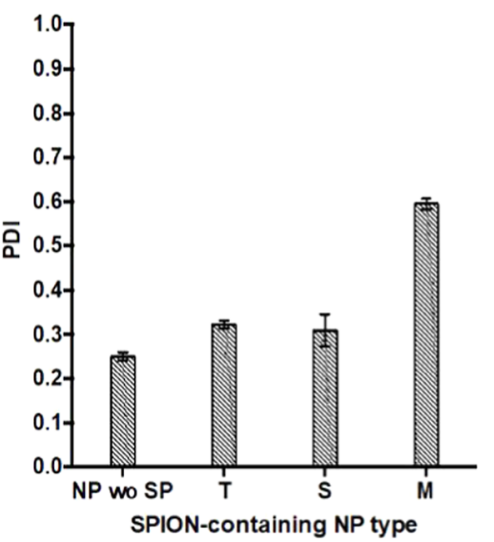

E

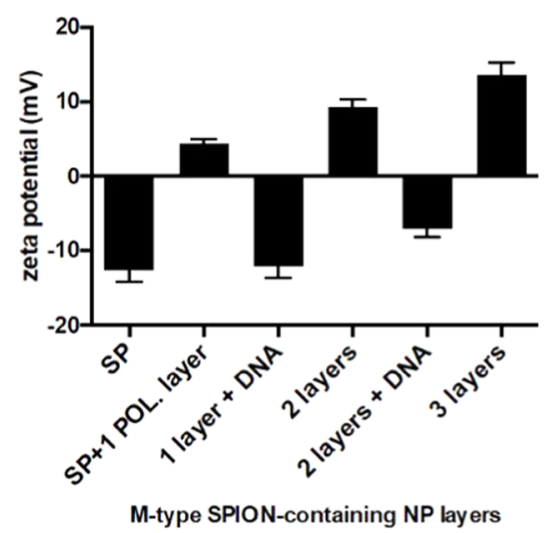

Figure 1. Manufacturing and characterization of SPION-containing nanoparticles. (A) Scheme of the different structures hypothesized for SPIONcontaining nanoparticles ( $\mathrm{T}=$ together nanoparticles; $\mathrm{S}=$ separate nanoparticles; and $\mathrm{M}=$ multicoating nanoparticles); (B) electrophoretic mobility shift assay (EMSA) of naked pGFP (pGFP) and the plasmid complexes with only pBAE (NP) and with pBAE + SPIONs, at the indicated concentrations, with the different types of structures ( $\mathrm{T}, \mathrm{S}$, or $\mathrm{M}$ ); (C) hydrodynamic diameter (in $\mathrm{nm}$ ) and $\zeta$-potential (in $\mathrm{mV}$ ), by dynamic light scattering (DLS) analysis, of nanoparticles without SPIONs and different SPION-containing nanoparticles at a fixed SPIONs' concentration; (D) polydispersity index (PDI) of the same nanoparticles; and (E) layer-by-layer (LbL) $\zeta$-potential analysis of M-type SPION-containing nanoparticles. All data correspond to mean \pm standard deviation $(\mathrm{SD})$ values of, at least, three replicates.

nanothermometry, magnetic separation, and bioremediation. ${ }^{47}$ Considering that such SPIONs are biocompatible and have been already used in biomedical applications, their use as gene delivery transfection agents has been proposed. It is worth noting that although the safety of SPIONs' characterization is simple in the current article, SPIONs are approved by the FDA and EMA to be used in humans, so their safety profile has been described earlier.

First, different strategies to form nanoparticles containing both pDNA and SPIONs to transfect a variety of cell lines have been explored, aiming at determining whether SPIONcontaining pBAE nanoparticles are able to enhance the efficiency of transfection from that of $\mathrm{pDNA} / \mathrm{pBAE}$ polyplexes.

Considering that pDNA can be encapsulated by means of cationic $\mathrm{pBAEs}^{20}$ and once we proved that SPIONs can be encapsulated as well (see Figure S1, Supporting Information), we explored different ways to form DNA-loaded SPIONcontaining nanocarriers. In particular, the three types of nanoparticles explained in the Materials section were formed and tested: (a) nanoparticles where the SPIONs and DNA were encapsulated by the polymer, named " $T$ " (together); (b) nanoparticles where the DNA was encapsulated by the polymer and then SPIONs were added to the solution, named " $S$ " (separated); (c) multicoating nanoparticles consisting of four layers: a nucleus formed by SPIONs, a polymer layer encapsulating this nucleus, a plasmid DNA layer, and another polymer layer to ensure the DNA encapsulation, named " $M$ " (Figure 1A).

$\mathrm{T}$ type of SPION-containing nanoparticles was formed following the most similar procedure to the SPION-free nanoparticles (NP without SP). First, a gel retardation assay confirmed the complexation of the plasmid with the pBAE polymer, without and with the presence of SPIONs (Figure 1B). As shown in Figure 1C, these nanoparticles showed a bigger hydrodynamic diameter than nanoparticles without SPIONs (NP wo SP) but in the acceptable size range and a positive surface potential. S-type nanoparticles are equally formed as the NPs with the exception that just when they precipitate, SPIONs are added to the solution. Thus, SPIONs are thought to be attached to the nanoparticle surface. These NPs showed almost the same size and $\zeta$-potential as nanoparticles without SP (NP wo SP). Although it could be expected a negative surface charge due to the hypothesized presence of the SPIONs at the external part of the nanoparticle, these nanoparticles remain cationic because we did not add enough SPIONs to form a continuous layer surrounding the whole nanoparticle surface. This was made to maintain the cationic character of the nanoparticles, required to enhance cell transfection. Finally, M-type SPIONcontaining NPs are the most differently formed from conventional DNA/pBAE NPs as they imply a layer-by-layer (LbL) deposition of the different elements. The LbL deposition of oppositely charged polyelectrolytes on the surface of condensed DNA or viral particles has been largely employed. ${ }^{48-50}$ However, $\mathrm{LbL}$ on the surface of inorganic nanoparticles, such as the SPIONs employed here or the gold nanoparticles, has recently attracted attention from researchers because of their capability to deliver therapeutic genes to human cells. ${ }^{24}$ Higher hydrodynamic diameter and PDI (Figure 1C,D) of these particles were expected because of the LbL procedure. ${ }^{51,52}$

Evidence of the LbL deposition could be observed analyzing the $\zeta$-potential of multicoating nanoparticles of C32-CR3/ $\mathrm{pBAE}$ at a weight ratio of 50:1 with the $\mathrm{pGFP}$ and at a SPION 


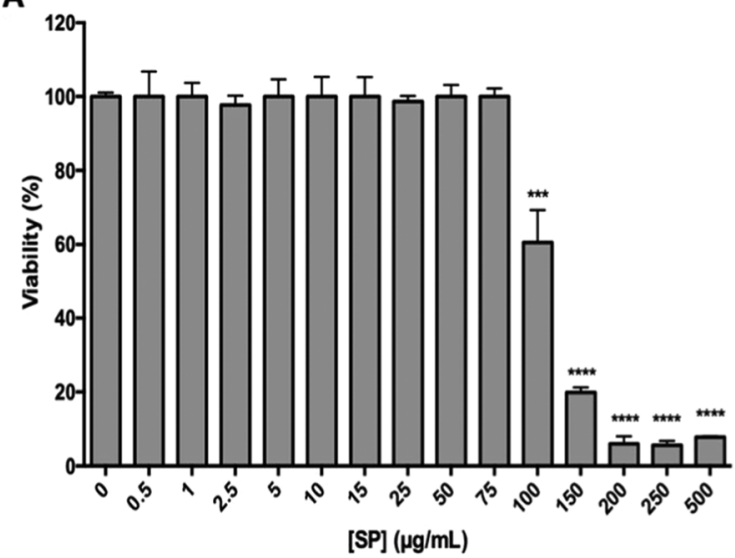

B

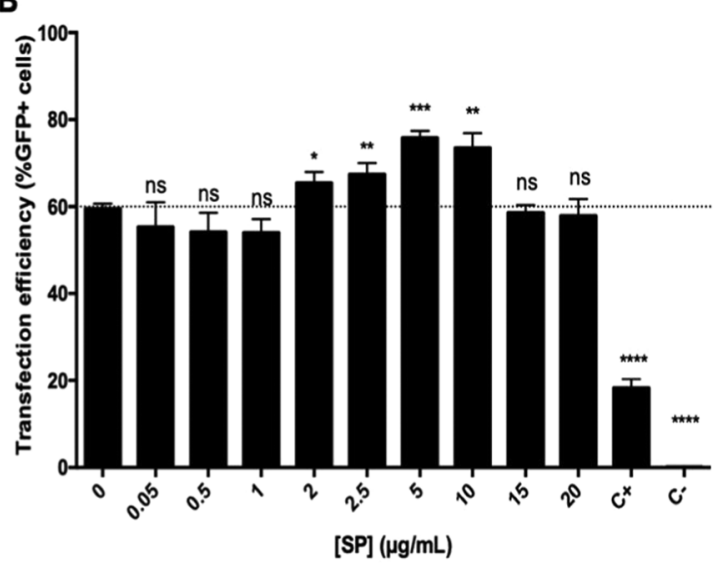

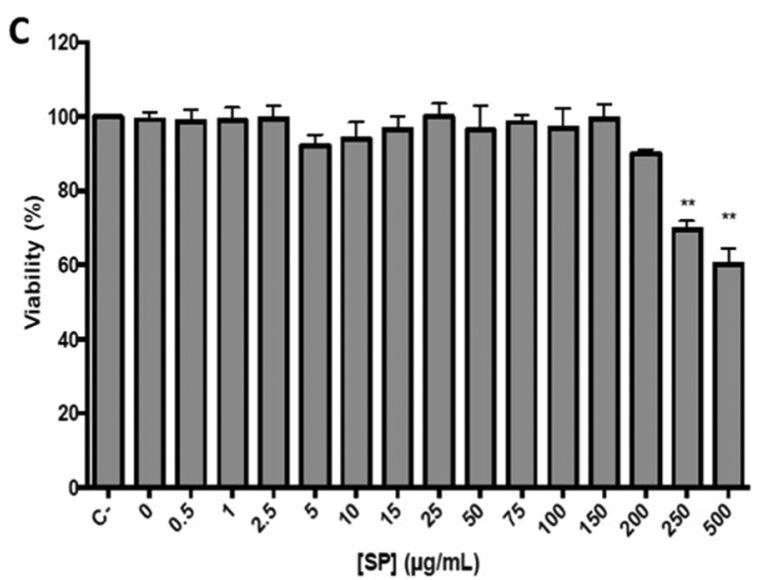

Figure 2. SPION cellular screenings. (A) MTT assay on Cos-7 cells to determine their tolerance to SPION concentration (SP); (B) fluorescenceactivated cell sorting (FACS) analysis regarding the transfection efficiency screening of different SPION concentrations into C32-CR3/pGFP (50:1) T nanoparticles; and (C) MTT assay on Cos-7 cells to determine their tolerance to C32-CR3/pGFP (50:1) T nanoparticles. Results correspond to at least three replicates performed in a single experiment. $t$-Test was applied in this experiment to find out significant differences. $\mathrm{C}^{+}=\mathrm{Lipofectamine}$ transfection reagent; $\mathrm{C}^{-}=$cells incubated with only media.

concentration of $5 \mu \mathrm{g} \mathrm{mL} \mathrm{mL}^{-1}$ (Figure $1 \mathrm{E}$ ). As previously mentioned, a nucleus of SPIONs, which are negatively charged due to its DMSA coating, was covered with an initial layer of polymer, which was positively charged, inducing a drastic change of the $\zeta$-potential of the nanoparticles formed, from clearly negative to positive values. Subsequent addition of DNA produced a change of the $\zeta$-potential from positive to negative, thus demonstrating that it was interacting with the positive nanoparticles previously formed. Similarly, further additions of either polymer or DNA layers switched the $\zeta$-potential of the polyplexes. The plot on Figure 1E shows the $\zeta$-potential switches derived from three polymer layers. However, because of their excessive size (see Figure S2, Supporting Information), M nanoparticles with three polymeric layers were not employed. Further experiments were carried out with two polymer layers of M-type nanoparticles, which are formed by a total of four layers including the SPION nucleus, the two polymeric layers, and the DNA layer.

SPIONs' Optimal Concentration for Transfection Assays. Once these three approaches to form SPIONcontaining nanoparticles were characterized in terms of size and polydispersity, their transfection efficiency was next analyzed. We first determined the optimal SPION concentrations to work with and then which type of SPION-containing nanoparticles should be chosen for further experiments.
First, cell viability was determined by 3-(4,5-dimethylthiazol2-yl)-2,5-diphenyltetrazolium bromide (MTT) assays on different cell cultures exposed to different SPION concentrations to assure that the internalization of SPIONs did not negatively impact cellular metabolism. As shown in Figure 2A, at concentrations up to $75 \mu \mathrm{g}$ of SPIONs $\mathrm{mL}^{-1}$, Cos-7 cells showed no signs of toxicity, and for HeLa cells, the tolerance raised up to $100 \mu \mathrm{g}$ of SPIONs $\mathrm{mL}^{-1}$ (see Figure S3, Supporting Information). This is in accordance with previous studies that report that some toxicity may be observed when concentrations of SPIONs exceed $100 \mu \mathrm{g} \mathrm{mL}^{-1}$ depending on the cell type. ${ }^{53}$

Then, a screening of different SPION concentrations into DNA/pBAE polyplexes was conducted with the aim to choose the ones showing more transfection efficiency. Considering the cell compatibility results obtained with the SPIONs (Figure 2A), a range between 0 and $20 \mu \mathrm{g}$ of SPIONs $\mathrm{mL}^{-1}$ was chosen. This experiment was performed with Cos-7 cells since they are considered a permissive cell line and with one common type of nanoparticles (T-type) for all the SPION concentrations. The other types of SPION-containing nanoparticles would be later deeply analyzed in terms of transfection efficiency. In parallel, viability of Cos-7 cells was also assessed when incubated with SPION-containing nanoparticles (specifically T-type) (Figure 2C). In this case, the results show that SPIONs' compatibility is enhanced probably due to their encapsulation inside the $\mathrm{pBAE}$ 
polymers, which were already demonstrated to be nontoxic at these concentrations. ${ }^{54,55}$

The expression of the reporter gene GFP was used to evaluate the transfection efficiency. Before quantifying GFP expression by flow cytometry, micrographs of the different conditions were taken to be able to compare qualitatively the transfection efficiency of each formulation tested (see Figure S4, Supporting Information). The results observed through fluorescence microscopy were quantitatively corroborated by FACS analysis, as shown in Figure 2B. Remarkably, this figure indicates that at a SPION concentration ranging between 2 and $10 \mu \mathrm{g} \mathrm{mL}^{-1}$, the transfection efficiency significantly increased in comparison to nanoparticles that do not contain SPIONs (NPs), indicating that probably below $2 \mu \mathrm{g}$ of SPIONs $\mathrm{mL}^{-1}$, the amount of these magnetic nanoparticles might not be enough to cause any effect on the cells. On the other hand, at concentrations higher than 10 $\mu \mathrm{g}$ of SPIONs $\mathrm{mL}^{-1}$, these magnetic nanoparticles (MNPs) may agglomerate, leading to inefficient uptake of polyplexes. This plot also reveals that the highest percentage of transfected cells was observed around $5 \mu \mathrm{g} \mathrm{mL}-1$ of SPIONs. From concentrations higher than $5 \mu \mathrm{g}$ SPIONs $\mathrm{mL}^{-1}$, transfection ratios decreased. Thereby, $0.5,2.5$, and $5 \mu \mathrm{g}$ of SPIONs $\mathrm{mL}^{-1}$ were the chosen concentrations to work with in further experiments. Interestingly, these working concentrations are far from the toxicity range of SPIONs showed in Figure 2A.

Transfection Screening of the Different SPIONContaining Nanoparticles. Once the SPION concentrations were established, the most efficient type of nanoparticle had to be chosen. To do so, Cos-7 cells were treated with the three types of nanoparticles formed at $0.5,2.5$, and $5 \mu \mathrm{g}$ of SPIONs $\mathrm{mL}^{-1}$. The transfection efficiencies of all the different conditions were first observed by fluorescence microscopy (Figure 3A) and then quantified by FACS (Figure 3B).

Given the results showed in Figure 3, S nanoparticles were chosen over $\mathrm{T}$ NPs because of their higher transfection efficiency at the two highest concentrations of SPIONs as compared to $\mathrm{T}$ nanoparticles. In addition, $\mathrm{S}$ nanoparticles' results showed lower variability than the ones from $\mathrm{T}$ NPs. Moreover, the presence of SPIONs not only improved cell transfection at the two highest concentrations, but also significantly enhanced cell transfection efficiency of S nanoparticles at all the concentrations tested as compared to nonloaded NPs. Therefore, in further cell transfections, this type of nanoparticles was selected.

On the other hand, despite not showing significant differences with NPs in two of the three concentrations of SPIONs tested, $\mathrm{M}$ nanoparticles were also chosen for further in vitro studies because of their singularity in their LbL structure. In many applications, this kind of structures could be very useful for the possibility to load different types of active principles in the different layers of the complex.

Cell Uptake Differences between SPIONs and SPIONContaining Nanoparticles. Once it was proven that the addition of SPIONs to the pBAE/DNA nanocarriers enhanced their cell transfection efficiency, and the optimal SPION concentration to work with was established, we aimed to demonstrate that a multicomponent nanoparticle comprising SPIONs, pBAE, and DNA would be more efficient in terms of cellular uptake than the bare SPIONs, which have been broadly employed as gene delivery systems complexing biological molecules such as antibodies, peptides, hormones, or drugs to their surface. ${ }^{56,57}$ To this end, the iron content of HeLa cells
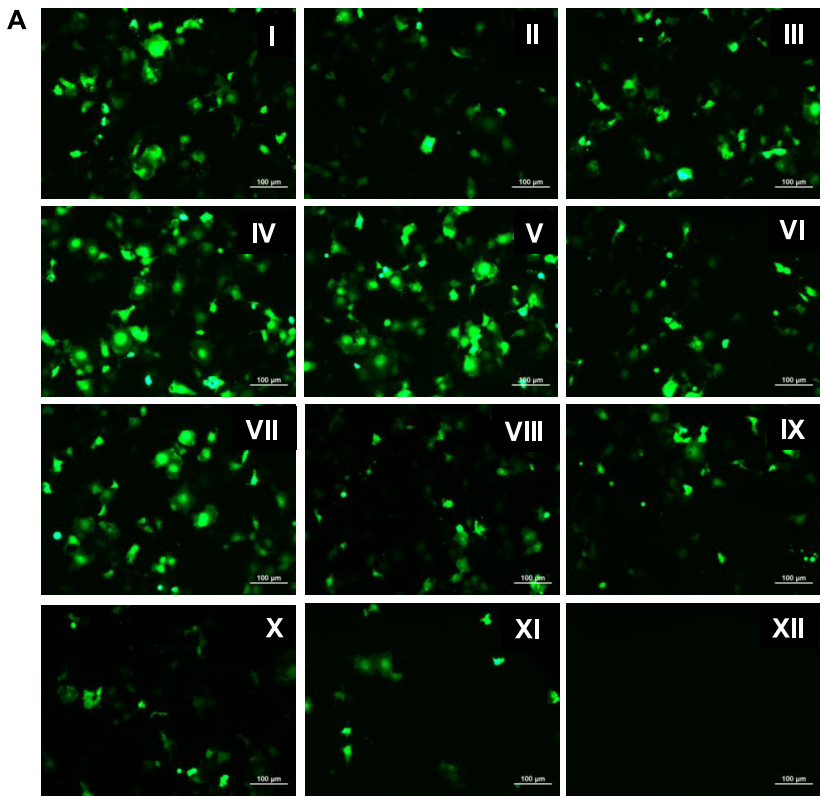

B

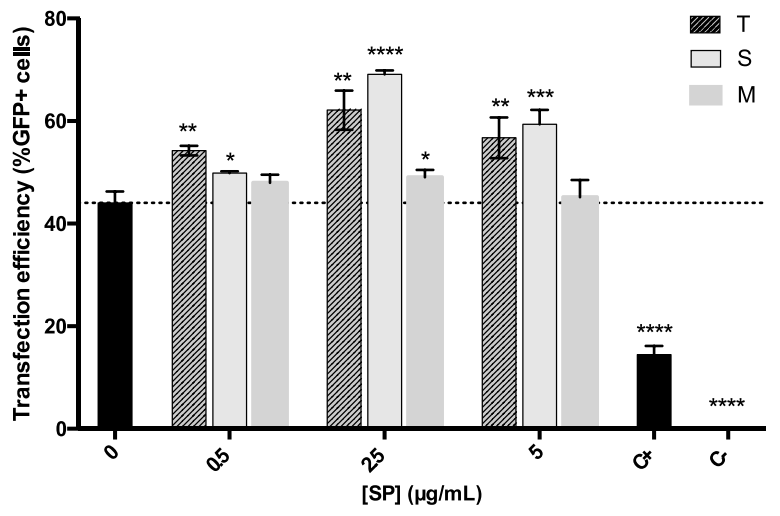

Figure 3. Transfection screenings of the different nanoparticles. (A) Fluorescence microscopy images (I): $0.5 \mathrm{~T}$; (II): $0.5 \mathrm{~S}$; (III): $0.5 \mathrm{M}$; (IV): $2.5 \mathrm{~T}$; (V): $2.5 \mathrm{~S}$; (VI): $2.5 \mathrm{M}$; (VII): $5 \mathrm{~T}$; (VIII): $5 \mathrm{~S}$; (IX): $5 \mathrm{M}$; (X) NPs without SPIONs; (XI): positive control of Lipofectamine; (XII): negative control of untreated cells and (B) FACS analyses of the $\mathrm{T}, \mathrm{S}$, and M C32-CR3/pGFP (50:1) nanoparticles' transfection on Cos-7 cells at different SPION concentrations. Results correspond to mean \pm SD values of at least three replicates. A $t$-test was performed here to find out significant differences. $T=$ together nanoparticles; $S=$ separate nanoparticles; $\mathrm{M}=$ multicoating nanoparticles; $\mathrm{C}^{+}=$ Lipofectamine transfection reagent; $\mathrm{C}^{-}=$cells incubated with only media.

treated with bare SPIONs and with SPION-containing S-type $\mathrm{NPs}$ was quantified $48 \mathrm{~h}$ after transfection.

Given that cells have a basal level of intracellular iron content, the obtained results were normalized so that only the excess of iron due to the presence of internalized magnetic nanoparticles is plotted. As it can be observed in Figure 4, cells treated with bare SPIONs (naked) at $2.5 \mu \mathrm{g}$ of SPIONs $\mathrm{mL}^{-1}$ internalized $4.91 \pm 2.02 \mathrm{pg}$ of $\mathrm{Fe} /$ cell more than untreated cells, whereas those treated with bare SPIONs at $5 \mu \mathrm{g} \mathrm{mL}^{-1}$ had a difference of $8.12 \pm 1.12 \mathrm{pg}$ of $\mathrm{Fe} / \mathrm{cell}$. On the other hand, C32-CR3/pGFP (50:1) $\mathrm{S}$ nanoparticles prepared at $2.5 \mu \mathrm{g}$ of SPIONs $\mathrm{mL}^{-1}$ had $7.03 \pm 1.25 \mathrm{pg}$ of $\mathrm{Fe} / \mathrm{cell}$ more than control cells, whereas those treated with the same nanoparticles prepared at $5 \mu \mathrm{g}$ of SPIONs $\mathrm{mL}^{-1}$ internalized $14.98 \pm 2.25 \mathrm{pg}$ of $\mathrm{Fe} /$ cell more. These results were in accordance with what was expected since the more the 


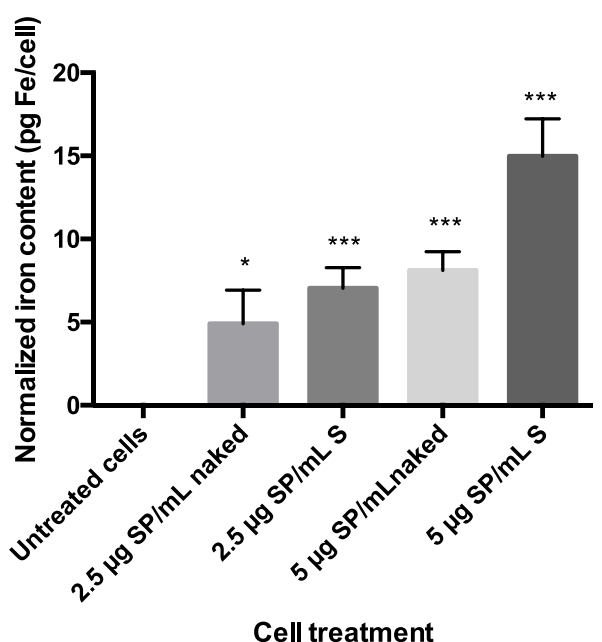

Figure 4. Inductively coupled plasma-optical emission spectrometry (ICP-OES): cellular iron content analysis of nanoparticles. Untreated cells' iron content was normalized to $0 \mathrm{pg}$ of $\mathrm{Fe} /$ cell. Results correspond to mean \pm SD of at least triplicates. Analysis of variance (ANOVA) was applied to find out statistical differences.

SPIONs were provided to the cells, the more the iron was internalized. In addition, several other studies have reported a range of $10-25 \mathrm{pg}$ of $\mathrm{Fe} /$ cell in HeLa cells (the same employed here) when SPIONs were used with a transfection agent. ${ }^{58-60}$

It is worth remarking the complementarity of ICP results with those of uptake and transfection experiments. Altogether, with these results, we are able to demonstrate that the three components of the complexes designed are efficiently internalized in cells: first, polymer uptake, although not studied, must take place to enable pGFP transfection, which is demonstrated in Figure 3. Finally, with ICP experiments, we also demonstrate that, at the same time, SPIONs are internalized even more efficiently if they are complexed with our nanoparticles.

The fact that the cells treated with complexed SPIONs showed more iron content compared to those treated with bare SPIONs at both SPION concentrations tested is, at first sight, surprising. We could hypothesize the following: since the coating of 2,3-dimercaptosuccinic acid (DMSA) causes SPIONs to be negatively charged, they may experiment repulsion with cell membranes. Thus, although it is not yet clear, it has been reported that the mechanism of cellular uptake of DMSASPIONs may be related to endocytosis. ${ }^{61}$ Moreover, such cell uptake pathways are susceptible to saturation. Therefore, it is most probable that a high concentration of free SPIONs (in the naked sample) will saturate the route of entry, and this may lead to a high number of SPIONs to remain in the extracellular media. In other words, when one single SPION-containing NP enters a cell, several SPIONs attached to the pBAE will enter at once. By contrast, the bare SPIONs have to be internalized one at a time by each cell receptor.

To sum up, these results indicate that more intracellular iron is obtained for a fixed concentration of SPIONs when these magnetic nanoparticles are complexed with pBAE and pDNA as compared to when SPIONs are internalized alone. Thus, in terms of cell uptake, the gene delivery system consisting of a multicomponent nanoparticle is more efficient than naked SPIONs. Besides that, results obtained so far suggest that SPIONs improve transfection. To confirm this unanticipated but desirable effect, more experiments were performed.
SPIONs Improve Cell Transfection of pBAE/pDNA

Polyplexes. Experiments detailed above suggested a positive effect of SPIONs on cell transfection. To confirm it, transfection efficiencies of $S$ and $M$ nanoparticles, prepared at $0.5,2.5$, and 5 $\mu \mathrm{g}$ of SPIONs $\mathrm{mL}^{-1}$, were studied in three different cell lines (Cos-7, HeLa, and U-87 MG). In particular, the expression of the reporter gene GFP was analyzed by fluorescence microscopy (see Figures S5-S10, Supporting Information) and through flow cytometry analysis. These experiments were performed using two different polymers: C32-CR3, abbreviated as C32-R; and C6-CR3, named C6-R. The latter was used because of its capability to form more stable nanoparticles due to its hydrophobic moiety, ${ }^{22}$ able to be lyophilized without changing their physicochemical properties. ${ }^{55}$ The balance between stability of the polyplexes and cytotoxicity would determine the best performing polymer for each cell line.

As mentioned before, Cos- 7 is considered as quite permissive to the transfection cell line. For this reason, these were the cells employed for preliminary experiments and the first ones to test the effect of SPIONs on cell transfection. Then, cells from a cervical cancer (HeLa), which are more difficult to transfect, ${ }^{21}$ were analyzed. Finally, the glioblastoma cell line U-87 MG was employed as a model of cells that are highly difficult to modify using nonviral vectors. ${ }^{62}$

As previously shown, SPIONs remarkably increased the transfection efficiency of C32-CR3 polyplexes in Cos-7 cells (Figures $2 \mathrm{~B}$ and $5 \mathrm{~A}$ ). The transfection efficiency of these polyplexes was almost doubled when 2.5 or $5 \mu \mathrm{g}$ of SPIONs $\mathrm{mL}^{-1}$ was added to the NPs, and for any of the three SPION concentrations tested, it was higher than when using NPs. No significant differences were observed between the two highest concentrations of SPIONs or between S and M nanoparticles. On the other hand, we also tested the C6-CR3 polymer. This polymer is very similar to C32, although due to modifications on its lateral chains, it is more hydrophobic (see chemical structure below, in Figure 7). This small change did not induce changes in the physicochemical properties of nanoparticles (data not shown). In the case of C6-CR3-based polyplexes (Figure 5D), differences were observed between the types of nanoparticles used: not all the nanoparticles tested increased the transfection efficiency of the nanoparticles without SPIONs. This only happened with 2.5 and $5 \mu \mathrm{g}$ of SPIONs $\mathrm{mL}^{-1}$ for $\mathrm{S}$ nanoparticles and $5 \mu \mathrm{g}$ of SPIONs $\mathrm{mL}^{-1}$ for M ones. Therefore, for C6-CR3based polyplexes, $5 \mu \mathrm{g}$ of SPIONs $\mathrm{mL}^{-1}$ was the optimal concentration of the three evaluated, and S NPs were the best type of nanoparticles. Since both concentrations showed similar results, we selected the one with the higher SPION loading to facilitate magnetic sorting in future experiments.

Regarding HeLa cells (Figure 5B,E), the transfection efficiency of C32-CR3 polyplexes was remarkably increased when 2.5 or $5 \mu \mathrm{g}$ of SPIONs $\mathrm{mL}^{-1}$ was added to the $\mathrm{S}$ nanoparticles or when $5 \mu \mathrm{g}$ of SPIONs $\mathrm{mL}^{-1}$ was added to the $\mathrm{M}$ ones. At this SPION concentration, S and M showed the same transfection efficiency, and at lower concentrations, the transfection was higher in $\mathrm{S}$ ones. In the case of C6-CR3 polyplexes, the transfection efficiency was only clearly increased with the S NPs at $5 \mu \mathrm{g}$ of SPIONs $\mathrm{mL}^{-1}$ (Figure $5 \mathrm{E}$ ).

Finally, the percentages of GFP expression of U-87 MG cells gave evidence of their reluctance to transfection (Figure 5C,F). However, the transfection efficiency of C32-CR3-based polyplexes on these cells was significantly enhanced by the presence of SPIONs at their highest concentration $\left(5 \mu \mathrm{g} \mathrm{mL}^{-1}\right)$ on $\mathrm{M}$ nanoparticles and at any of the concentrations tested for $\mathrm{S}$ 


\section{C32-CR3}

A

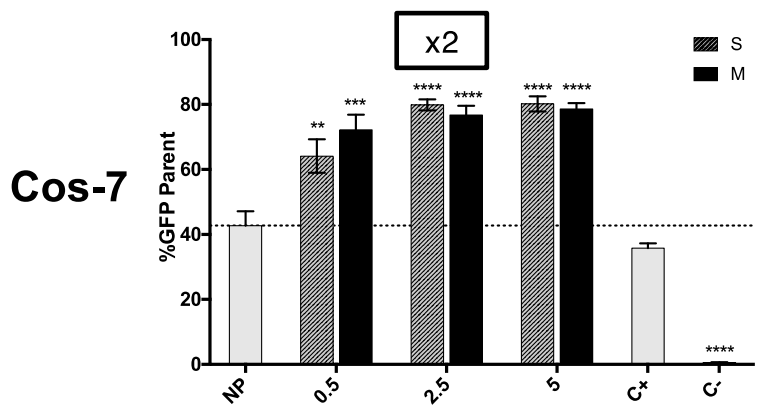

B

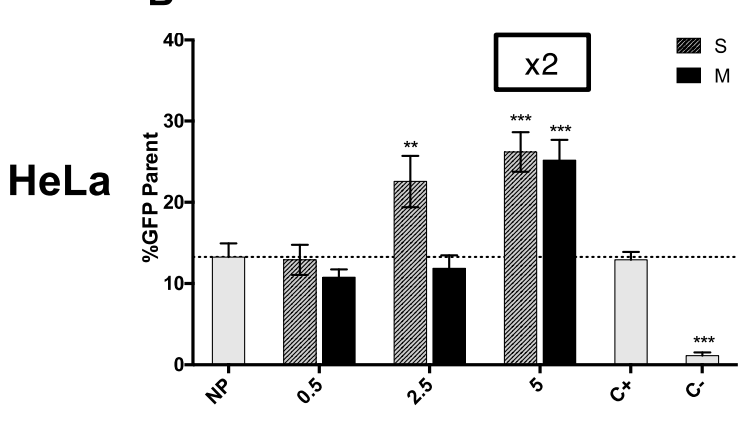

C

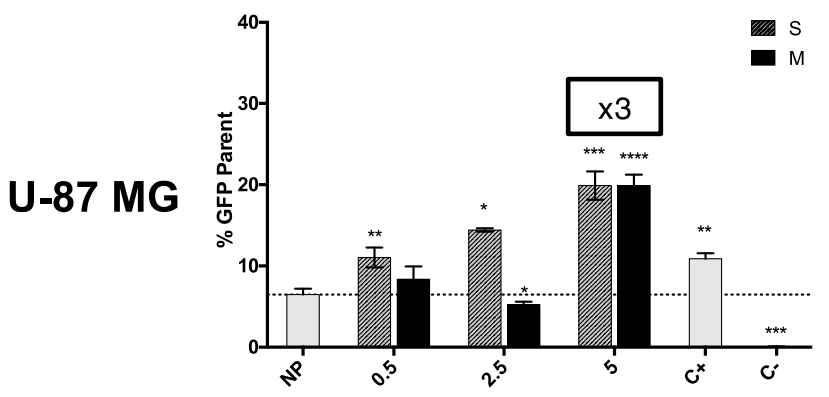

C6-CR3

D

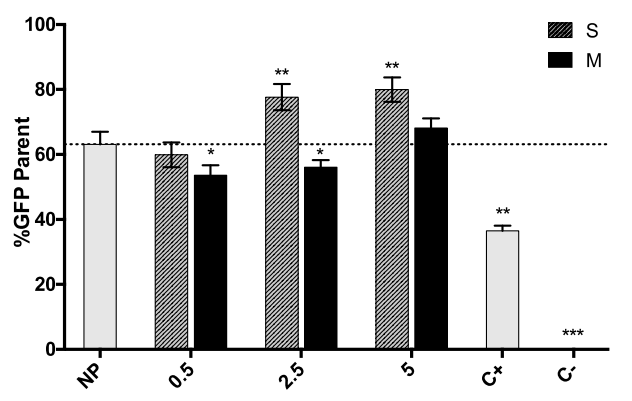

E

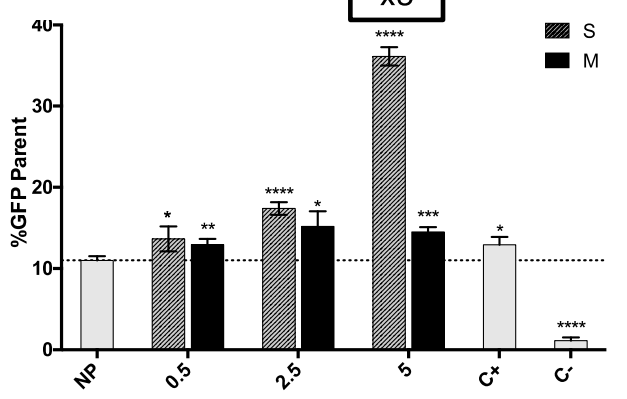

F

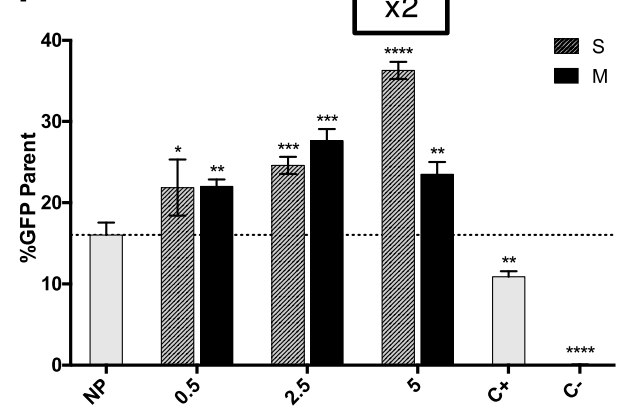

Figure 5. Transfection efficiency results of S- and M-type C32-CR3/pGFP (50:1) (A-C) and C6-CR3/pGFP (25:1) (D, E) SPION-containing nanoparticles into Cos-7 (A and D), HeLa (B and E), and U-87 MG cells ( C and F). Values correspond to the mean \pm SD of triplicates of the same experiment. A $t$-test was applied to find out statistical differences. $\mathrm{S}=$ separate nanoparticles; $\mathrm{M}=$ multicoating nanoparticles; $\mathrm{C}^{+}=\mathrm{Lipofectamine}$ transfection reagent; $\mathrm{C}^{-}=$cells incubated with only media. Scale bars are different depending on cell line to facilitate the reading.

nanoparticles. The optimal SPION concentration was clearly 5 $\mu \mathrm{g} \mathrm{mL} L^{-1}$, and at this concentration, $\mathrm{S}$ and $\mathrm{M}$ nanoparticles showed 3-fold enhanced transfection efficiency. The transfection efficiency of C6-CR3-based polyplexes without SPIONs (NP) was higher than that of C32-CR3 ones on U-87 MG cells. Regarding SPIONs, they had a positive effect on transfection efficiency on these cells for any concentration and any type of C6-CR3-based SPION-containing nanoparticles tested. Interestingly, $\mathrm{S}$ nanoparticles with $5 \mu \mathrm{g}$ of SPIONs $\mathrm{mL}^{-1}$ showed the best result, doubling the transfection efficiency of NP. In conclusion, SPIONs show a clear enhancer effect on the transfection of U-87 MG cells.

The fact that in the three cell lines tested, C6-CR3 polyplexes without SPIONs (NPs) showed higher or at least the same transfection efficiencies as C32-CR3s was not surprising. Also, C6-based polyplexes in general needed higher amounts of SPIONs to show significantly increased transfection efficacy. It has been discussed that although not all the combinations between DNA, pBAEs, and SPIONs tested were able to significantly enhance cellular transfection, the clear majority of them did show higher transfection efficiency than the same NPs only combining pBAE with DNA (NP). This assertion applies to the two types of nanoparticles tested ( $S$ and $M)$, although better results were obtained with the $S$ ones. Thereby, the transfection efficiency enhancer effect of SPIONs in Cos-7, HeLa, and U-87 MG cell lines was clearly proven.

Taking an overview of the three cell lines tested, it is possible to assert that in the case of a permissive cell line as Cos-7, the best performing SPION-containing nanoparticle tested (C32 5S) can duplicate the transfection capability of C32-CR3-NP. However, in cells that are more difficult to transfect, such as U$87 \mathrm{MG}$ or HeLa, which show a transfection efficiency of around $10 \%$ when using NPs without SPIONs, the effect of the presence of SPIONs in the polyplexes can achieve 3-fold higher values of transfection efficiency. Thereby, although the absolute values of transfection on such cell lines are much lower than in Cos-7 cells, the increase in cell transfection efficiency due to the presence of SPIONs is higher. These are encouraging results regarding cell 
therapy strategies since the cells that are used for these purposes usually show high reluctance to genetic modification.

It is worth remarking that transfection efficiency could be even improved by adding a magnetic field when performing the transfection to facilitate the movement of the SPIONs. However, in the present study it was not used since the capacity of the whole complexes to transfect cells was the factor to study, without external forces, with the aim to compare with particles without SPION loading.

Magnetic Cell Sorting. As mentioned before, the second major point of the present work is to select those genetically modified cells benefiting from the magnetism of SPIONcontaining NPs. To do so, magnetic columns were used due to their ability to recover the magnetic fraction, ease of preparation, capacity to work with high number of cells, and allowance of a rapid and efficient cell separation. The first parameter evaluated was the expression of GFP before performing the sorting and in both fractions (magnetic and nonmagnetic) obtained after the sorting (Figure 6A).

As Figure 6A shows, $\mathrm{S}$ nanoparticles, as well as the $\mathrm{M}$ ones, showed significantly increased levels of GFP expression on their magnetic fractions as compared to the nonsorted samples. Accordingly, the eluted or nonmagnetic fraction showed lower
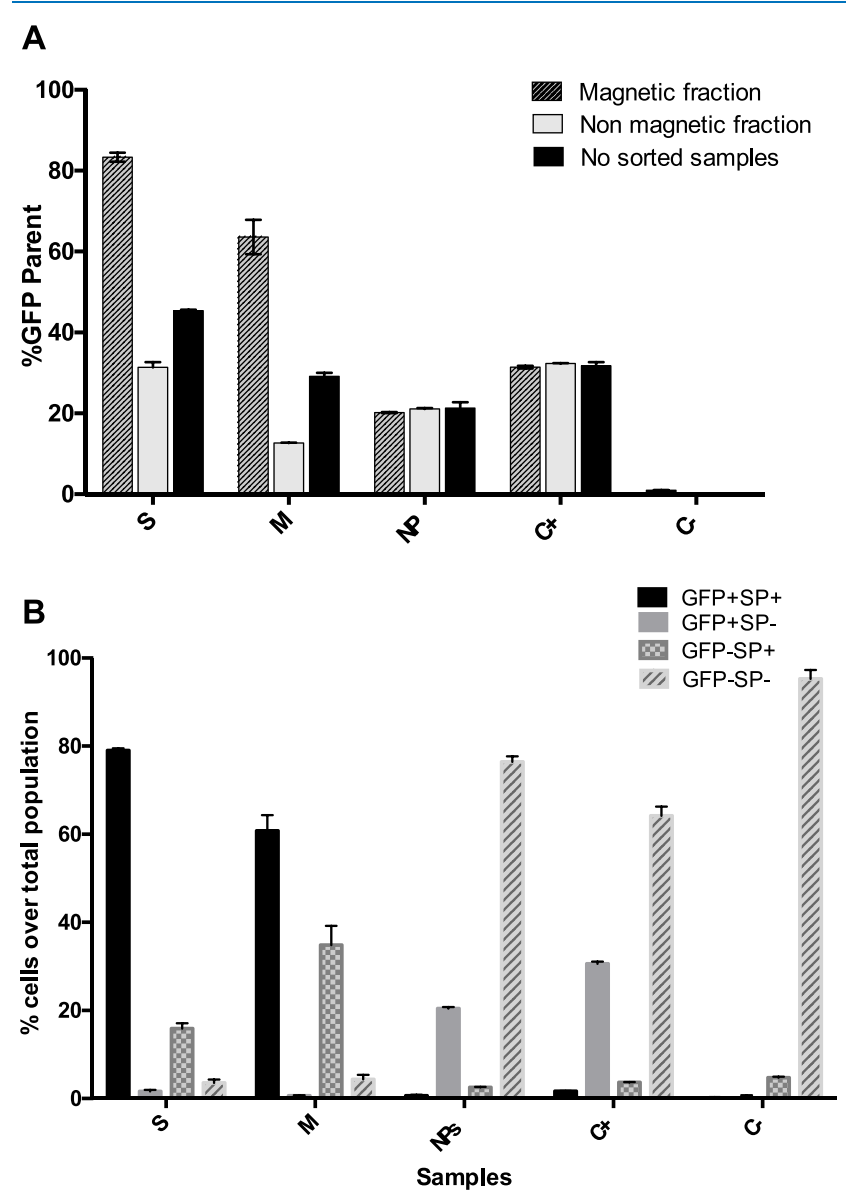

Figure 6. Magnetic cell sorting. FACS analysis regarding (A) the transfection efficiencies of C6-CR3 $S$ and $M$ nanoparticles on both magnetically sorted and nonsorted HeLa cells and (B) each fraction of sorted HeLa cells treated with $S$ and $M$ nanoparticles. Results are presented as mean \pm SD of triplicates. $S=$ separate nanoparticles; $M=$ multicoating nanoparticles; $\mathrm{C}^{+}=$Lipofectamine transfection reagent; $\mathrm{C}^{-}=$cells incubated with only media. transfection efficiency. By contrast, negative and positive controls and NP (samples without SPIONs) maintained their GFP expression levels in both sorted and nonsorted cells, thus demonstrating that sorting does not negatively affect cell transfection.

Next, the magnetic labeling of cells was evaluated. To do so, the number of cells was normalized between the magnetic and the nonmagnetic fraction of the different conditions, and the percentage of each fraction was plotted (see Figure S11, Supporting Information). Once the transfection efficiency and the magnetic labeling were analyzed, we next evaluated what percentage from the total number of cells did represent every category (Figure 6B), namely, (a) cells expressing GFP and magnetically labeled $\left(\mathrm{GFP}+\mathrm{SP}^{+}\right)$; (b) cells expressing GFP but not magnetically labeled $\left(\mathrm{GFP}+\mathrm{SP}^{-}\right)$; $(\mathrm{c})$ cells not expressing GFP but magnetically labeled $\left(\mathrm{GFP}-\mathrm{SP}^{+}\right)$; and $(\mathrm{d})$ cells that neither express GFP nor were magnetic $\left(\mathrm{GFP}-\mathrm{SP}^{-}\right)$. The first fraction $\left(\mathrm{GFP}+\mathrm{SP}^{+}\right)$would contain the desired cells, being both magnetic (have internalized SPIONs) and genetically modified (express GFP coded by the pDNA). For further clinical applications, enriching this fraction might be very important to ensure that all the cells reimplanted in a patient are carrying the therapeutic gene and therefore increase the probability of success of the therapy. Collecting these four fractions from the total number of cells allowed us to discard false-positive and -negative events.

Figure $6 \mathrm{~B}$ shows that the fraction of cells expressing GFP and being magnetically labeled $\left(\mathrm{GFP}+\mathrm{SP}^{+}\right)$represented almost $80 \%$ in the case of cells treated with $S$ nanoparticles. Cells treated with $\mathrm{M}$ nanoparticles showed around $60 \%$ of this "desired fraction", where both transfection and magnetic labeling had occurred. These results confirm the usability of our system. On the other hand, the fraction of cells that were magnetic but not transfected (GFP $-\mathrm{SP}^{+}$) represents the false-positive events. Since previous studies report that in cell therapy applications stem cells could favor tumor self-growth in vivo, ${ }^{63}$ the percentage of cells in this fraction should be reduced. To this purpose, an appealing strategy could be the covalent attachment of the magnetic nanoparticles to the polymer.

On the other hand, as shown in Figure 6B, the nonmagnetic fraction of samples without SPIONs (NPs, $\mathrm{C}^{+}$, and $\mathrm{C}^{-}$) represented most of the cells. In the case of NP and $\mathrm{C}^{+}$, these nonmagnetic cells were distributed between the $\mathrm{GFP}^{+}$and the $\mathrm{GFP}^{-}$fraction, according to their transfection efficiency, whereas in the case of $\mathrm{C}^{-}$, the cells were $\mathrm{GFP}^{-}$in large majority. To sum up, this magnetic sorting has allowed the massive separation of each sample into four fractions according to transfection efficiency and magnetic labeling of cells, showing promising results.

Overall, the obtained results have revealed the enhancer effect of SPIONs on the transfection of both permissive and reluctant to transfection cell lines. Furthermore, the presence of SPIONs in the polyplexes allowed not only such unexpected increase of cell transfection but also the selective magnetic separation of genetically modified cells. The enrichment of the transfected cell fraction might be crucial for further clinical cell therapy applications, and therefore the results presented here open the door to SPION-containing nanoparticles as promising tools for stem cell-based therapies.

\section{EXPERIMENTAL SECTION}

Materials. Reagents and solvents used for synthesis were purchased from Sigma-Aldrich. Plasmid pmaxGFP (3486 bp) 


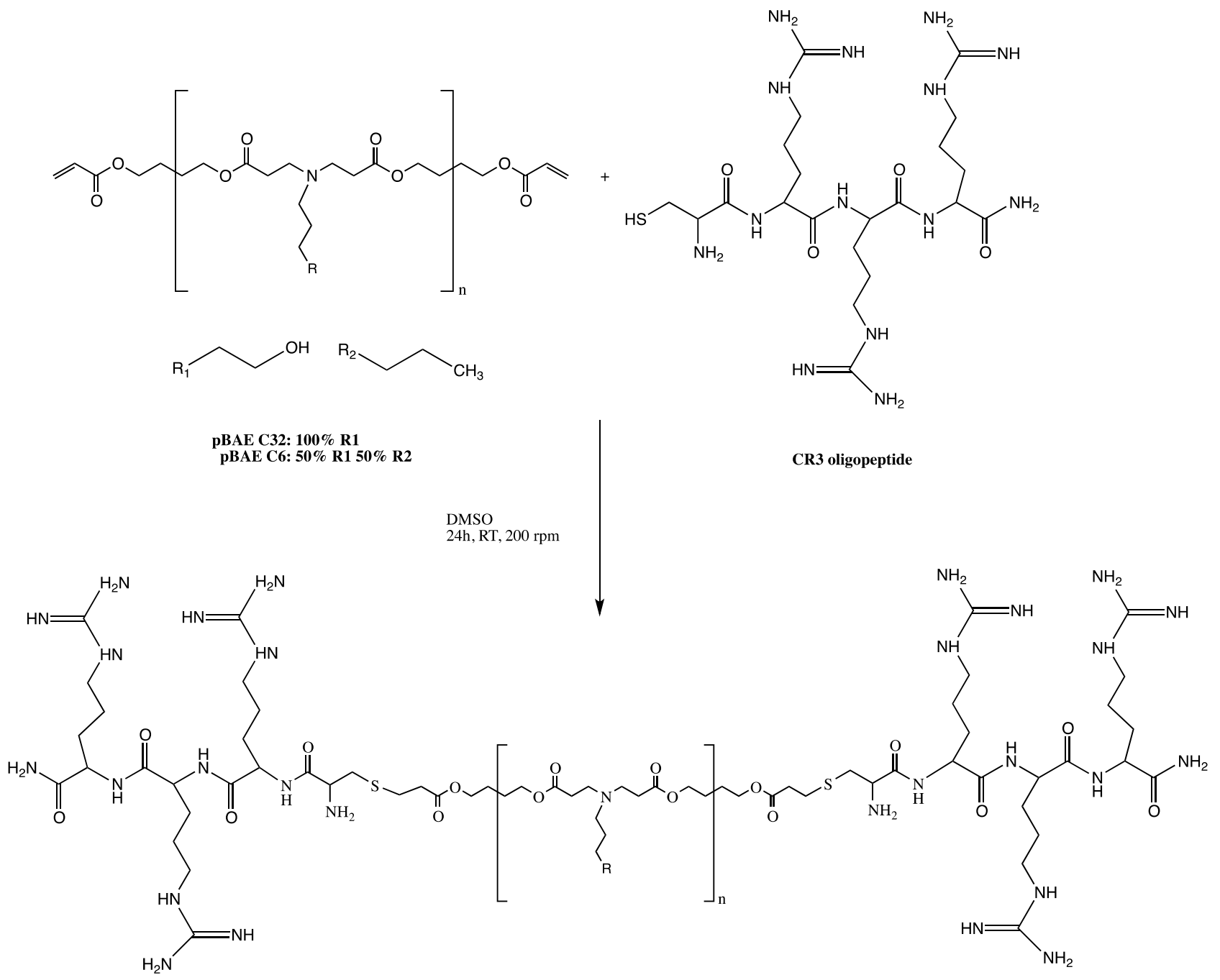

CR3-modified PBAE

Figure 7. Chemical structures of C32CR3 and C6CR3 OM-pBAEs, indicating the C32 and C6 initial polymers reacting with the CR3 peptide.

was obtained from Amaxa. CR3 $\left(\mathrm{NH}_{2}-\mathrm{Cys}-\mathrm{Arg}-\mathrm{Arg}-\mathrm{Arg}-\right.$ $\mathrm{COOH})$ and $\mathrm{CD} 3\left(\mathrm{NH}_{2}-\mathrm{Cys}-\mathrm{Asp}-\mathrm{Asp}-\mathrm{Asp}-\mathrm{COOH}\right)$ peptides were obtained from GL Biochem Ltd (Shangai) and transferred to hydrochloride salt form before use. DMSA-coated SPIONs (hydrodynamic size $=45 \mathrm{~nm}$; surface charge $=-12$ $\mathrm{mV}$; stock SPION dispersion, dispersed in water as the dispersant) were performed by Unit 9 of the Platform of Production of Biomaterials and Nanoparticles of the NANBIOSIS ICTS, by the Superficies y Particulas Nanoestructuradas del Instituto de Nanociencia de Aragón (PI J. Santamaría) group. $^{44,45}$ Cos-7, HeLa, and U-87 MG cells were obtained from ATCC (Manassas, VA). Products for cell culture (media, phosphate-buffered saline (PBS), glutamine, penicillin-streptomycin solution, Lipofectamine 2000) were obtained from Gibco, Hyclone, and Invitrogen. SYBR Safe was obtained from Invitrogen (CA). Magnetic and sterile-stored MS Columns were purchased from Miltenyi Biotec S.L. (Bergisch Gladbach, Germany).

Synthesis of pBAE Nanoparticles. Apart from the three different approaches to form SPION-containing nanoparticles that are detailed hereafter, $\mathrm{pDNA} / \mathrm{pBAE}$ nanoparticles (without SPIONs) were employed as controls in most of the transfection experiments of this work. First, oligopeptide-modified $\operatorname{poly}(\beta$ - amino ester)s (OM-pBAEs) were synthesized following a twostep procedure as described by Segovia et al. ${ }^{20}$ Then, the polyplexes (also referred to as NPs) were prepared following Dosta et al.'s protocol. ${ }^{21}$ Two polymer backbones, C32 and C6, were used (see Figure 7), both with Cys + 3Arg as terminal peptides in both edges. Polymer characterization is presented in our previous publications. ${ }^{20,21,55}$ In brief, they were prepared at a 50:1 C32CR3/pDNA or 25:1 C6CR3/pDNA weight ratio by mixing equal volumes of pDNA at $1 \mathrm{mg} \mathrm{mL}^{-1}$ with the polymer at $100 \mathrm{mg} \mathrm{mL}^{-1}$ in $25 \mathrm{mM}$ AcONa buffer solution. The pDNA was added over the polymer solution and mixed by pipetting, followed by $30 \mathrm{~min}$ incubation at $25{ }^{\circ} \mathrm{C}$. For the formation of discrete structures, this mixture was diluted in a 20 -fold volume of serum-free Dulbecco's modified Eagle's medium (DMEM, 4.5 g glucose $\mathrm{mL}^{-1}$ without glutamine, $\mathrm{pH}=7.2$ ) prior to each transfection or in a 10-fold volume of phosphate-buffered saline (PBS, $1 \times, \mathrm{pH}=7.4$ ) prior to its physicochemical characterization.

SPION-Containing Nanoparticle Synthesis. Three types of these nanoparticles were formed and tested (see Figure 1A). All these nanoparticles were freshly prepared in sodium acetate buffer solution $(25 \mathrm{mM}, \mathrm{pH}=5.5)$ and incubated for $30 \mathrm{~min}$ at $25{ }^{\circ} \mathrm{C}$. The complexes polymer/DNA/SPIONs were synthe- 
tized mixing equal volumes of polymer solution with DNA and/ or SPION solution at different ratios. The synthesis of $50 \mu \mathrm{L}$ of S-type C32-CR3/pGFP (50:1) SPION-containing nanoparticles at $5 \mu \mathrm{g}$ of SPIONs $\mathrm{mL}^{-1}$ is described in detail as an example. One Eppendorf was prepared with $25 \mu \mathrm{L}$ of pGFP DNA solution in sodium acetate buffer $25 \mathrm{mM}$ to get a concentration of $3 \times 10^{-2} \mu \mathrm{g}$ of DNA $\mu \mathrm{L}^{-1}$. Another Eppendorf was prepared using $0.75 \mu \mathrm{L}$ of C32-CR3 at $100 \mathrm{mg} \mathrm{mL}^{-1}$ diluted in sodium acetate buffer $25 \mathrm{mM}$ at $25 \mu \mathrm{L}$ final volume. The Eppendorf containing the DNA solution was homogenized with a micropipette, and its whole volume $(25 \mu \mathrm{L})$ was added to the polymer solution Eppendorf, which had just been vortexed for $10 \mathrm{~s}$. This mixture was incubated at $25{ }^{\circ} \mathrm{C}$ for $30 \mathrm{~min}$. For the formation of discrete structures, nanoparticles were then further diluted in a 10-fold volume of PBS or 20-fold volume of DMEM, and the necessary volume of SPIONs was added to have a final concentration of $5 \mu \mathrm{g}$ of SPIONs $\mathrm{mL}^{-1}$.

Gel Retardation Assays. Gel retardation assays or electrophoretic mobility shift assays (EMSA) were performed to confirm the complexation of plasmids with polymers and SPIONs. T-, S-, and M-type nanoparticles were used. The polymer to pDNA ratio was fixed at 50:1 (w/w) with 2.5 or $5 \mu \mathrm{g}$ $\mathrm{mL}^{-1}$ SPIONs. $\mathrm{pBAE} / \mathrm{pDNA}$ complexes were freshly prepared and added to wells of agarose gel $(0.8 \%$, SYBR Safe used as stainer). Samples were run at $80 \mathrm{~V}$ for $30 \mathrm{~min}$ (Apelex PS 305, France) and visualized by UV illumination.

Physicochemical Characterization of Nanoparticles. The particle average hydrodynamic diameter (size) of the nanoparticles was determined by dynamic light scattering (DLS) using Zetasizer nano ZS (Malvern Instruments Ltd., United Kingdom, $4 \mathrm{~mW}$ laser). All the measurements were performed at $25{ }^{\circ} \mathrm{C}$ with $30 \mathrm{~s}$ equilibrium time using a laser wavelength of $633 \mathrm{~nm}$. Correlation functions were collected at a scattering angle of $173^{\circ}$, and Malvern particle sizing software (DTS version 5.03) was used to determine the particle hydrodynamic size. The equipment was set to perform three measures, each of which consists of 10 cycles of measurements. The final size value of each sample was equivalent to the mean of these three measures \pm standard deviation. The size distribution was given by the polydispersity index (PDI). The samples to analyze by DLS were prepared by diluting $100 \mu \mathrm{L}$ of nanoparticle solution (in acetate buffer) in $1 \mathrm{~mL}$ of final volume of PBS $1 \times$ to simulate the cellular environment. The surface charge $(\zeta$-potential) of the SPIONs/pBAE/DNA polyplexes was determined from the electrophoretic mobility by means of the Smoluchowski equation. ${ }^{64}$ The $\zeta$-potential measurements for each sample were performed in triplicates, and every measurement consisted in 20 cycles of an applied electric field. For these measures, $800 \mu \mathrm{L}$ of the previously diluted nanoparticles was added into a $\zeta$-potential cuvette.

Cell Culture. Cos-7 (ATCC CRL-1651), HeLa (ATCC CCL-2), and U87MG (ATCC HTB-14) cell lines were cultured with DMEM (4.5 g glucose $\mathrm{mL}^{-1}$ without glutamine, $\mathrm{pH}=7.2$ ) supplemented with $10 \%$ fetal bovine serum (FBS), $1 \%$ penicillin-streptomycin mixture, and the amino acid glutamine $\left(2 \mathrm{mmol} \mathrm{L}{ }^{-1}\right)$. Cells were grown on incubators at $37^{\circ} \mathrm{C}$ with $5 \%$ $\mathrm{CO}_{2}$ atmosphere during successive passages and always seeded $24 \mathrm{~h}$ before starting any experiment.

In Vitro Cellular Viability and Transfection. Cells were seeded in 96- and 24-well plates (only for cell sorting experiments) at a concentration of $4 \times 104$ cells $\mathrm{cm}^{-2}$. SPION-containing pBAEs/DNA nanoparticles were prepared as described above using pGFP. Polyplexes were further diluted in serum-free DMEM at a final concentration of $1.5 \mu \mathrm{g}$ pGFP $\mathrm{mL}^{-1}$. Then, cells were washed with PBS, and for a 96-well plate, $200 \mu \mathrm{L}$ of the nanoparticle solution was added to each well at a final pGFP concentration of $0.3 \mu \mathrm{g}$ per well or $0.1 \mu \mathrm{g} \mathrm{mL}^{-1}$ in the case of encapsulated pDNA for Lipofectamine 2000 as the positive control (optimal concentration recommended by the manufacturer, lower than that used for our nanoparticles due to toxicity of Lipofectamine, which does not enable the increase of the pDNA concentration). Untreated cells were used as negative controls (results normalized to $100 \%$ viability, used to compare the absorbance of the tested samples). Cells were incubated for 2 $\mathrm{h}$ at $37{ }^{\circ} \mathrm{C}$ in $5 \% \mathrm{CO}_{2}$ atmosphere. Subsequently, transfection media was removed and fresh supplemented media was added to the cells. After $48 \mathrm{~h}$ incubation in the presence of FBS, cell viability and transfection efficiency were measured.

3-(4,5-Dimethylthiazol-2-yl)-2,5-diphenyltetrazolium bromide (MTT) was used to quantify cell viability. ${ }^{65}$ Cells cultivated in 96-well plates were treated with different concentrations of SPIONs and incubated for $48 \mathrm{~h}$ at $37{ }^{\circ} \mathrm{C}$ and $5 \% \mathrm{CO}_{2}$. Then, they were washed with PBS and incubated in complete medium supplemented with MTT solution $(0.5 \mathrm{mg}$ $\mathrm{mL}^{-1}$ ), added at $10 \% \mathrm{v} / \mathrm{v}$ for $3 \mathrm{~h}$ at $37^{\circ} \mathrm{C}$ and $5 \% \mathrm{CO}_{2}$. DMSO was then added to solubilize the insoluble formazan crystals formed. Absorbance was measured (Elx808 Biotek Instruments Ltd) at a wavelength of $550 \mathrm{~nm}$, and values were converted to percentages of cell viability relative to untreated cells by normalizing with the absorbance of nontreated cells.

Transfection efficiency was measured by flow cytometry (FACS; in a BD Fortessa cell analyzer). Forty-eight hours after transfection, cells were incubated for $5 \mathrm{~min}$ with trypsinethylenediaminetetraacetic acid at $37^{\circ} \mathrm{C}$ in $5 \% \mathrm{CO}_{2}$ atmosphere and fixed with previously filtered paraformaldehyde $(0.22 \mu \mathrm{m}$, $2 \%$ in PBS). GFP expression was quantified and compared against a negative control of untreated cells and either a positive control of Lipofectamine 2000 or a control of pBAE/pGFP nanoparticles without SPIONs (NPs).

Inductively Coupled Plasma-Optical Emission Spectrometry. The iron content of the cells treated with SPIONs or SPION-containing nanoparticles was determined through an inductively coupled plasma-optical emission spectrometry (ICP-OES). Cells were seeded on a 24-well plate, and a transfection procedure was performed as describe above. Subsequently, cells were gently washed with PBS to eliminate the SPIONs that were not internalized. Then, cells were trypsinized and digested with an oxidative mixture of hydrogen peroxide $(30 \% \mathrm{v} / \mathrm{v})$ and nitric acid $(50 \% \mathrm{v} / \mathrm{v})$ while heating until nitrous vapors were observed. The obtained sample was diluted to a final volume of $10 \mathrm{~mL}$ and a nitric acid concentration lower than $5 \%$. The iron content, in terms of $\mathrm{mg}$ of iron per $\mathrm{mL}$, was calculated by an Optima 2100 DV ICP analyzer (PerkinElmer, Waltham, Massachusetts). Finally, the amount of iron/cell (in pg per cell) was determined according to the number of cells seeded and normalizing the untreated cells (control) as zero pg of iron/cell.

Magnetic Cell Sorting. HeLa cells, were transfected with different transfection agents: C6CR3-bsed nanoparticles without SPIONS (NP), S- and M-type nanoparticles at $5 \mu \mathrm{g}$ of SPIONS $\mathrm{mL}^{-1}(\mathrm{~S}$ and $\mathrm{M})$, and lipofectamine $2000\left(\mathrm{C}^{+}\right)$. After that they were trypsinized and fixed and further sorted using MS columns. For these sorting experiments, 24-well plates were employed. For each sample, a new column was used. First, the column was placed in direct contact with strong magnets and it was equilibrated by loading $1 \mathrm{~mL}$ of previously filtered PBS. The 
sample was then loaded, and the eluted fraction (nonmagnetic cells) was collected. Then, the magnet was removed, the column was placed on another Falcon tube, and the retained fraction (magnetic cells) was eluted by adding $2 \mathrm{~mL}$ of PBS and pressing the plunger. Thus, two fractions were obtained from each sorted sample. Apart from the sorted samples, replicates that were not sorted were also prepared. Then, these nonsorted samples together with the magnetic and nonmagnetic fractions of each sorted sample were centrifuged at $1000 \mathrm{rpm}$ for $5 \mathrm{~min}$. The supernatant was discarded until only $200 \mu \mathrm{L}$ of media or PBS was left, and the pellet was resuspended. This was analyzed by flow cytometry (FACS) in terms of GFP expression and number of cells, and it was possible to determine whether the SPIONs and the DNA/pBAE complexes entered together in the cells or not.

Statistical Analysis. GraphPad Prism software was used for the statistical analysis. Two-way ANOVA and $t$-test were applied to find out statistical differences between groups or between each condition as compared to the control group, respectively. The significance of the difference in the data is $* p<0.05, * * p<$ 0.01 , $* * * p<0.001$, and $* * * * p<0.0001$ regarding controls of untreated cells $\left(\mathrm{C}^{-}\right)$or cells treated with $\mathrm{DNA} / \mathrm{pBAE}$ nanoparticles without SPIONs (NPs), depending on the experiment.

\section{CONCLUSIONS}

In this work, three types of SPION-containing nanoparticles with potential as gene delivery carriers have been successfully developed. Physicochemical characterization and in vitro screenings have confirmed their suitability as nucleic acid delivery vectors. Then, this assumption has been evaluated in different cell cultures, and it has been demonstrated that the presence of SPIONs on OM-pBAE/pDNA polyplexes has an enhancer effect on the transfection of both permissive and reluctant to transfection cell lines. It has been also reported here a synergic relationship between pBAEs and SPIONs: in the $\mathrm{pBAE} / \mathrm{pDNA} / \mathrm{SPIONs}$ system, namely, SPIONs help pBAEs in terms of transfection, whereas pBAEs help SPIONs in the cellular internalization. Furthermore, the presence of SPIONs in these polyplexes has allowed not only this unanticipated increase of cell transfection but also the selective magnetic separation of genetically modified cells from the ones that do not contain the foreign DNA. Since the enrichment of the transfected cell fraction might be crucial for further clinical cell therapy applications, the results here presented open the door to SPION-containing nanoparticles as promising tools for cell therapy approaches.

\section{ASSOCIATED CONTENT}

\section{S Supporting Information}

The Supporting Information is available free of charge on the ACS Publications website at DOI: 10.1021/acsomega.8b02905.

Figure S1, $\zeta$-potential comparison of the C32CR3 titrations over AAV, DMSA-SPIONs, and C32CD3; Figure S2, hydrodynamic diameter (in nanometer) by DLS analysis of each layer of M-type nanoparticles; Figure S3, MTT assay on HeLa cells to determine their tolerance to SPIONs; Figure S4, fluorescence microscopy images of the T-nanoparticles' transfections on Cos-7 cells; SPION concentrations, in $\mu \mathrm{g} \mathrm{mL}^{-1}$, are as follows: (I): NP without SPIONs; (II): 0.05; (III): 0.5; (IV): 1; (V): 2; (VI): 2.5; (VII): 5; (VIII): 10; (IX): 15; (X); 20; (XI): positive control of cells treated with Lipofectamine; (XII): negative control of untreated cells; Figure S5, fluorescence microscopy images of the S and M C32CR3/pGFP (50:1) nanoparticle transfections on Cos-7 cells at different SPION concentrations: (I): 0.5 S; (II): $2.5 \mathrm{~S}$; (III): $5 \mathrm{~S}$; (IV): $0.5 \mathrm{M}$; (V): $2.5 \mathrm{M}$; (VI): $5 \mathrm{M}$; (VII): NPs without SPIONs; (VIII): positive control of Lipofectamine; (IX): negative control of untreated cells; Figure S6, fluorescence microscopy images of the S and M C6-CR3/pGFP (50:1) nanoparticle transfections on Cos7 cells at different SPION concentrations: (I): $0.5 \mathrm{~S}$; (II): $2.5 \mathrm{~S}$; (III): $5 \mathrm{~S}$; (IV): $0.5 \mathrm{M}$; (V): $2.5 \mathrm{M}$; (VI): $5 \mathrm{M}$; (VII): NPs without SPIONs; (VIII): positive control of Lipofectamine; (IX): negative control of untreated cells; Figure S7, fluorescence microscopy images of the $S$ and $M$ C32-CR3/pGFP (50:1) nanoparticle transfections on HeLa cells at different SPION concentrations: (I): $0.5 \mathrm{~S}$; (II): $2.5 \mathrm{~S}$; (III): $5 \mathrm{~S}$; (IV): $0.5 \mathrm{M}$; (V): $2.5 \mathrm{M}$; (VI): $5 \mathrm{M}$; (VII): NPs without SPIONs; (VIII): positive control of Lipofectamine; (IX): negative control of untreated cells; Figure S8, fluorescence microscopy images of the $S$ and $M$ C6-CR3/pGFP (50:1) nanoparticle transfections on HeLa cells at different SPION concentrations: (I): 0.5 S; (II): $2.5 \mathrm{~S}$; (III): $5 \mathrm{~S}$; (IV): $0.5 \mathrm{M}$; (V): $2.5 \mathrm{M}$; (VI): 5 M; (VII): NPs without SPIONs; (VIII): positive control of Lipofectamine; (IX): negative control of untreated cells; Figure S9, fluorescence microscopy images of the S and M C32-CR3/pGFP (50:1) nanoparticle transfections on U-87 MG cells at different SPION concentrations: (I): 0.5 S; (II): 2.5 S; (III): 5 S; (IV): $0.5 \mathrm{M}$; (V): $2.5 \mathrm{M}$; (VI): $5 \mathrm{M}$; (VII): NPs without SPIONs; (VIII): positive control of Lipofectamine; (IX): negative control of untreated cells; Figure S10, fluorescence microscopy images of the $S$ and M C6-CR3/pGFP (50:1) nanoparticle transfections on U-87 MG cells at different SPION concentrations: (I): $0.5 \mathrm{~S}$; (II): $2.5 \mathrm{~S}$; (III): $5 \mathrm{~S}$; (IV): $0.5 \mathrm{M}$; (V): $2.5 \mathrm{M}$; (VI): $5 \mathrm{M}$; (VII): NPs without SPIONs; (VIII): positive control of Lipofectamine; (IX): negative control of untreated cells; Figure S11, magnetic cell labeling of HeLa cells after Miltenyi sorting; the values are the mean \pm SD of experiments carried out in triplicate; $\mathrm{C}^{+}$are cells treated with Lipofectamine and $\mathrm{C}^{-}$are untreated cells (PDF)

\section{AUTHOR INFORMATION}

\section{Corresponding Author}

*E-mail: salvador.borros@iqs.url.edu.

ORCID

Jesús Santamaría: 0000-0002-8701-9745

Salvador Borrós: 0000-0002-4003-0381

\section{Notes}

The authors declare no competing financial interest.

\section{ACKNOWLEDGMENTS}

Financial supports from MINECO/FEDER (grants RTC-20153751-1, SAF2015-64927-C2-1-R, and SAF2015-64927-C2-2-R) and Instituto de Salud Carlos III (Red Temática de Investigación Cooperativa en Terapia Celular-TERCEL and TRANSMAG transference project from CIBER-BBN) are acknowledged. CIBER-BBN is an initiative funded by the VI National R\&D\&I Plan2008-2011, Iniciativa Ingenio 2010, Consolider Program, CIBER Actions, and financed by the 
Instituto de Salud Carlos III with assistance from the European Regional Development Fund. L.B. is grateful to IQS for their Predoctoral Grant (Ajuts IQS pels Estudis de Doctrorat). C.F. is grateful to MINECO for their Postdoctoral Fellowship (grant Torres Quevedo 2015). The Support of Agència de Gestió d'Ajuts Universitaris i de Recerca (AGAUR) from Generalitat de Catalunya is acknowledged for their support through SGR 2014 1170 grant.

\section{REFERENCES}

(1) Kamen, A.; Henry, O. Development and optimization of an adenovirus production process. J. Gene Med. 2004, 6, 184-192.

(2) Martin, M. E.; Rice, K. G. Peptide-guided gene delivery. AAPS J. 2007, 9, E18-E29.

(3) Agirre, M.; et al. Low molecular weight chitosan (LMWC)-based polyplexes for pDNA delivery: From bench to bedside. Polymers 2014, 6, 1727-1755

(4) Lyons, M.; et al. Adenovirus Type 5 Interactions with Human Blood Cells May Compromise Systemic Delivery. Mol. Ther. 2006, 14, 118-128.

(5) Pringle, I. A.; Hyde, S. C.; Gill, D. R. Non-viral vectors in cystic fibrosis gene therapy: recent developments and future prospects. Expert Opin. Biol. Ther. 2009, 9, 991-1003.

(6) Carlisle, R. C.; Benjamin, R.; Briggs, S. S.; Sumner-Jones, S.; McIntosh, J.; et al. Coating of adeno-associated virus with reactive polymers can ablate virus tropism, enable retargeting and provide resistance to neutralising antisera. J. Gene Med. 2008, 10, 400-411.

(7) McCrudden, C.; McCarthy, H. Cancer Gene Therapy-Key Biological Concepts in the Design of Multifunctional Non-Viral Delivery Systems; InTech, 2013.

(8) Yin, H.; et al. Non-viral vectors for gene-based therapy. Nat. Rev. Genet. 2014, 15, 541-555.

(9) Yang, Z.; et al. Multifunctional non-viral gene vectors with enhanced stability, improved cellular and nuclear uptake capability, and increased transfection efficiency. Nanoscale 2014, 6, 10193-10206.

(10) Foldvari, M.; et al. Non-viral gene therapy: Gains and challenges of non-invasive administration methods. J. Controlled Release 2016, 165-190.

(11) Elouahabi, A.; Ruysschaert, J. M. Formation and intracellular trafficking of lipoplexes and polyplexes. Mol. Ther. 2005, 11, 336-347.

(12) Guerrero-Cázares, H.; et al. Biodegradable polymeric nanoparticles show high efficacy and specificity at DNA delivery to human glioblastoma in vitro and in vivo. ACS Nano 2014, 8, 5141-5153.

(13) Oberli, M. A.; et al. Lipid Nanoparticle Assisted mRNA Delivery for Potent Cancer Immunotherapy. Nano Lett. 2017, 17, 1326-1335.

(14) Merdan, T.; Kopecek, J.; Kissel, T. Prospects for cationic polymers in gene and oligonucleotide therapy against cancer. Adv. Drug Delivery Rev. 2002, 54, 715-758.

(15) Lorenzer, C.; Dirin, M.; Winkler, A. M.; Baumann, V.; Winkler, J. Going beyond the liver: Progress and challenges of targeted delivery of siRNA therapeutics. J. Controlled Release 2015, 203, 1-15.

(16) Li, L.; Wei, Y.; Gong, C. Polymeric nanocarriers for non-viral gene delivery. J. Biomed. Nanotechnol. 2015, 11, 739-770.

(17) Kozielski, K. L.; Tzeng, S. Y.; Hurtado De Mendoza, B. A.; Green, J. J. Bioreducible cationic polymer-based nanoparticles for efficient and environmentally triggered cytoplasmic siRNA delivery to primary human brain cancer cells. ACS Nano 2014, 8, 3232-3241.

(18) Tzeng, S. Y.; Green, J. J. Subtle Changes to Polymer Structure and Degradation Mechanism Enable Highly Effective Nanoparticles for siRNA and DNA Delivery to Human Brain Cancer. Adv. Healthcare Mater. 2013, 2, 468-480.

(19) Green, J. J.; Langer, R.; Anderson, D. G. A combinatorial polymer library approach yields insight into nonviral gene delivery. Acc. Chem. Res. 2008, 41, 749-759.

(20) Segovia, N.; Dosta, P.; Cascante, A.; Ramos, V.; Borrós, S. Oligopeptide-terminated poly $(\beta$-amino ester $)$ s for highly efficient gene delivery and intracellular localization. Acta Biomater. 2014, 10, 21472158.
(21) Dosta, P.; Segovia, N.; Cascante, A.; Ramos, V.; Borrós, S. Surface charge tunability as a powerful strategy to control electrostatic interaction for high efficiency silencing, using tailored oligopeptidemodified poly(beta-amino ester)s (PBAEs). Acta Biomater. 2015, 20, $82-93$.

(22) Dosta, P.; Ramos, V.; Borrós, S. Stable and efficient generation of poly $(\beta$-amino ester $)$ s for RNAi delivery. Mol. Syst. Des. Eng. 2018, 3, 677-689.

(23) Sharpe, M.; Mount, N. Genetically modified T cells in cancer therapy: opportunities and challenges. Dis. Models Mech. 2015, 8, 337350.

(24) Bishop, C. J.; Tzeng, S. Y.; Green, J. J. Degradable polymercoated gold nanoparticles for co-delivery of DNA and siRNA. Acta Biomater. 2015, 11, 393-403.

(25) Pan, D.; Lanza, G. M.; Wickline, S. A.; Caruthers, S. D. Nanomedicine: Perspective and promises with ligand-directed molecular imaging. Eur. J. Radiol. 2009, 70, 274-285.

(26) Lammers, T.; Aime, S.; Hennink, W. E.; Storm, G.; Kiessling, F. Theranostic nanomedicine. Acc. Chem. Res. 2011, 44, 1029-1038.

(27) Gage, F. H.; Kawaja, M. D.; Fisher, L. J. Genetically modified cells: applications for intracerebral grafting. Trends Neurosci. 1991, 14, 328-333.

(28) Hidai, C.; Kitano, H. Nonviral Gene Therapy for Cancer: A Review. Diseases 2018, 6, No. 57.

(29) Porada, C. D.; Almeida-porada, G. Mesenchymal Stem Cells as Gene Delivery Vehicles. In Gene Therapy-Tools and Potential Applications; InTech, 2013.

(30) Calne, R. Y.; Gan, S. U.; Lee, K. O. Stem cell and gene therapies for diabetes mellitus. Nat. Rev. Endocrinol. 2010, 6, 173-177.

(31) Ren, C.; Xu, K.; Segal, D. J.; Zhang, Z. Strategies for the Enrichment and Selection of Genetically Modified Cells. Trends Biotechnol. 2019, 37, 56-71.

(32) Sun, R.; et al. Advances in stem cell therapy for cardiovascular disease (Review). Int. J. Mol. Med. 2016, 38, 23-29.

(33) Gómez-Barrena, E.; et al. Bone regeneration: Stem cell therapies and clinical studies in orthopaedics and traumatology. J. Cell. Mol. Med. 2011, 15, 1266-1286.

(34) Im, G.-I.; Shin, K.-J. Epigenetic approaches to regeneration of bone and cartilage from stem cells. Expert Opin. Biol. Ther. 2015, 15, 181-193.

(35) Quail, D.; Joyce, J. Microenvironmental regulation of tumor progression and metastasis. Nat. Med. 2013, 19, 1423-1437.

(36) Wiedenmann, J.; Oswald, F.; Nienhaus, G. U. Fluorescent proteins for live cell imaging: Opportunities, limitations, and challenges. IUBMB Life 2009, 61, 1029-1042.

(37) Tamanaha, C. R.; Mulvaney, S. P.; Rife, J. C.; Whitman, L. J. Magnetic labeling, detection, and system integration. Biosens. Bioelectron. 2008, 24, 1-13.

(38) Chen, C. C. V.; et al. Simple SPION Incubation as an Efficient Intracellular Labeling Method for Tracking Neural Progenitor Cells Using MRI. PLoS One 2013, 8, 1-11.

(39) Gobbo, O. L.; Sjaastad, K.; Radomski, M. W.; Volkov, Y.; PrinaMello, A. Magnetic Nanoparticles in Cancer Theranostics. Theranostics 2015, 5, 1249-1263.

(40) Petri-Fink, A.; Chastellain, M.; Juillerat-Jeanneret, L.; Ferrari, A.; Hofmann, H. Development of functionalized superparamagnetic iron oxide nanoparticles for interaction with human cancer cells. Biomaterials 2005, 26, 2685-2694.

(41) Prosen, L.; et al. Magnetofection: A reproducible method for gene delivery to melanoma cells. Biomed Res. Int. 2013, 6-8.

(42) Kami, D.; et al. Application of magnetic nanoparticles to gene delivery. Int. J. Mol. Sci. 2011, 12, 3705-3722.

(43) Berry, C. C. Progress in functionalization of magnetic nanoparticles for applications in biomedicine. J. Phys. D: Appl. Phys. 2009, 198, No. 224003.

(44) Grilc, J. G. V.; Zadnlk, B. Extraction of Acetic Acid from Dilute Aqueous Solutions with Trioctylphosphine Oxide. Ind. Eng. Chem. Process Des. Dev. 1981, 20, 433-435. 
(45) Roca, A. G.; et al. Surface functionalization for tailoring the aggregation and magnetic behaviour of silica-coated iron oxide nanostructures. Nanotechnology 2012, 23, No. 155603.

(46) Calero, M.; et al. Characterization of interaction of magnetic nanoparticles with breast cancer cells. J. Nanobiotechnol. 2015, 13, No. 16.

(47) Ruiz, A.; et al. Magnetic nanoparticles coated with dimercaptosuccinic acid: development, characterization, and application in biomedicine. J. Nanopart. Res. 2014, 16, No. 2589.

(48) Lvov, Y.; et al. Successive Deposition of Alternate Layers of Polyelectrolytes and a Charged Virus. Langmuir 1994, 10, 4232-4236.

(49) Decher, G. Fuzzy Nanoassemblies: Toward Layered Polymeric Multicomposites. Science 1997, 277, 1232-1237.

(50) Trubetskoy, V. S.; Loomis, A.; Hagstrom, J. E.; Budker, V. G.; Wolff, J. A. Layer-by-layer deposition of oppositely charged polyelectrolytes on the surface of condensed DNA particles. Nucleic Acids Res. 1999, 27, 3090-3095.

(51) Elbakry, A.; et al. Layer-by-layer assembled gold nanoparticles for siRNA delivery. Nano Lett. 2009, 9, 2059-2064.

(52) Deng, Z. J.; et al. Layer-by-layer nanoparticles for systemic codelivery of an anticancer drug and siRNA for potential triple-negative breast cancer treatment. ACS Nano 2013, 7, 9571-9584.

(53) Arbab, A.; et al. In Vivo Cellular Imaging for Translational Medical Research. Curr. Med. Imaging Rev. 2009, 5, 19-38.

(54) Dosta, P.; Segovia, N.; Cascante, A.; Ramos, V.; Borrós, S. Acta Biomaterialia Surface charge tunability as a powerful strategy to control electrostatic interaction for high efficiency silencing, using tailored oligopeptide- modified poly(beta-amino ester)s (PBAEs). Acta Biomater. 2015, 20, 82-93.

(55) Fornaguera, C.; et al. mRNA Delivery System for Targeting Antigen-Presenting Cells In Vivo. Adv. Healthcare Mater. 2018, No. 1800335.

(56) Shevtsov, M.; et al. Tumor targeting using magnetic nanoparticle Hsp70 conjugate in a model of C6 glioma. Neuro-Oncology 2014, 16, $38-49$.

(57) Singh, N.; Jenkins, G. J. S. S.; Asadi, R.; Doak, S. H. Potential toxicity of superparamagnetic iron oxide nanoparticles (SPION). Nano Rev. 2010, 1, 1-15.

(58) Frank, J. A.; et al. Magnetic intracellular labeling of mammalian cells by combining (FDA-approved) superparamagnetic iron oxide MR contrast agents and commonly used transfection agents. Acad. Radiol. 2002, 9, 484-487.

(59) Arbab, A. S.; et al. Intracytoplasmic tagging of cells with ferumoxides and transfection agent for cellular magnetic resonance imaging after cell transplantation: Methods and techniques. Transplantation 2003, 76, 1123-1130.

(60) Mailänder, V.; Landfester, K. Interaction of Nanoparticles with Cells. Biomacromolecules 2009, 2379-2400.

(61) Gu, J. L.; et al. The internalization pathway, metabolic fate and biological effect of superparamagnetic iron oxide nanoparticles in the macrophage-like RAW264.7 cell. Sci. China: Life Sci. 2011, 54, 793805.

(62) An, S.; et al. Nonviral gene therapy in vivo with PAM-RG4/ apoptin as a potential brain tumor therapeutic. Int. J. Nanomedicine 2013, 8, No. 821.

(63) Zhu, W.; et al. Mesenchymal stem cells derived from bone marrow favor tumor cell growth in vivo. Exp. Mol. Pathol. 2006, 80, 267-274.

(64) Wiersema, P. H.; Loeb, A. L.; Overbeek, J. T. G. Calculation of the electrophoretic mobility of a spherical colloid particle. J. Colloid Interface Sci. 1966, 22, 78-99.

(65) Putnam, D.; Gentry, C. A.; Pack, D. W.; Langer, R. Polymerbased gene delivery with low cytotoxicity by a unique balance of sidechain termini. Proc. Natl. Acad. Sci. U.S.A. 2001, 98, 1200-1205. 